\title{
Sciendo
}

DOI 10.2478/afepuc-2019-0001

(C) Acta Facultatis Educationis Physicae Universitatis Comenianae 2019, 59(1): 1-12

\section{PHYSIOLOGICAL ASPECTS AND INJURIES IN MIXED MARTIAL ARTS}

\author{
Petr Schlegel, Adam Křehký \\ Faculty of Education, University of Hradec Králové, Hradec Králové, Czech Republic
}

\begin{abstract}
Summary: Mixed Martial Arts (MMA) has become an independent sport discipline with its own distinctive aspects. It can no longer be perceived as before, as a compilation of other martial arts. MMA shows originality in training methods, health aspects, performance requirements or even moral-volitional qualities. The aim of the paper is to analyse the physiological aspects of MMA in both training and combat loads, to discuss the issue of injuries in MMA and to provide a comparison with other martial arts. Studies focusing directly on MMA wrestlers have been selected. These have included both amateur and professional athletes. The databases Pubmed, Scopus, Web of Science, and Scholar were used as sources. MMA ranks among sports with high-intensity workload, wrestlers achieve high levels of lactate and other metabolic markers. They need above-average aerobic capacity and perform well in upper body strength tests. Injury rates in MMA do not differ significantly from those in professional-level martial arts. Most injuries are associated with lacerations on the head. The requirements of extensive workload during performance must be reflected in training. Encouragement of aerobic and anaerobic endurance abilities in conjunction with optimum strength training seems crucial. It is essential to include prophylaxis as regards head concussions and strive for maximum safety of the sportsman during combat. Further research is required to confirm some of the conclusions, the limitations of which are due to the number and quality of the selected studies.
\end{abstract}

Keywords: mixed martial arts, physiology, injury 


\section{Introduction}

Mixed martial arts is a relatively young sport discipline. Its recent history can be dated back to the 1990s. The birth of MMA is associated with an American organization called UFC (Ultimate Fighting Championship), which organized its first event, in 1993 (Savage-West 2015). Growing popularity brought about a rapid boom and the number of fans rocketed, as the current transmissions of foreign and domestic gala evenings show.

Although there were tendencies throughout the world towards combats with rules more lenient than those of current traditional sports, the course of MMA was set by the USA. From the very beginning, MMA had many opponents because of the toughness of combats, which led to its ban in 40 US states. Over the years, with the growing number of supporters, the rules have stabilized and UFC together with other organizations have created a recognized sport discipline. Gradual amendments of rules concerned especially wrestler's safety (e.g. attack aimed at the eyes or neck, kicking a lying opponent) (Lystad 2014). This is also a reason why research dealing with MMA environment appears as late as long after 2000.

At the beginning, MMA was perceived as a compilation of individual martial arts, which was reflected in the approach to training. Over time, however, an independent discipline has formed, the performance and training principles of which cannot be easily transferred from other sports (martial arts).

During the analysis, research of "similar" sports, such as boxing, kick-boxing, GrecoRoman wrestling, judo, etc. were also used to a certain extent, due to lack of direct MMA studies. However, the conclusions can be applied only partially (although some elements are very similar).

From a varied spectrum of analyzable aspects of a particular sport discipline, physiological workload and the issue of injuries were chosen. The conclusions drawn from their analysis capture important health aspects and may be used for refining the workload during training or combat. The text below focuses mainly on MMA wrestlers and their environment during training or combat. The used source databases were Scopus, PubMed, Web of Science, Scholar.

\section{Physiology}

MMA is classified among sports with high demands on high-intensity performance. The usual structure of a match is three five-minute rounds with one-minute breaks in-between (with 
an exception of championship matches, which have five rounds). However, also ten-minute rounds may be seen (see the Rizin organization), which to some extent change the concept of the match. It is obvious even to a regular viewer that the workload is high and associated with strength and fitness effort (Schick, 2012). It is difficult to interpret the course of the match from the aspect of physiological processes due to its enormous variability. Wrestlers may fight in a separated stand-up position, in clinching position, on the ground, or in various combinations. This places different requirements on the aspects of strength, fitness, and coordination.

The common approach to setting optimum training loads is to get close to the official match. Amtman (2008) observed the differences in the workload of a circular training with specific elements of combat sports, a 2 × 4 min sparring match and an interval protocol Tabata $8 \times 20-10$ s. Lactate levels and RPE (rating of perceived exertion) values on the Borg scale were the outcome measures. Lactate levels of the sample $(n=6)$ reached $8.1-19.7$ and $10.2-$ 20.7 mmol. $\mathrm{l}^{-1}$ after sparring, which correlated with Borg values of 15 - 19 and 13 - 19, respectively. The values reached in Tabata intervals were lower. The resulting low values were due to prematurely terminated sparring in some cases (submission, knock out). Therefore, sparring must be well-organized, otherwise the sportsman may fail to achieve the desired workload. This applies to both the wrestler who gains the upper hand and to his opponent.

In a pilot study (Brasweel 2013), selected physical parameters were measured in MMA fighters and compared to those of karate fighters. Neither anthropometric parameters nor stress test results (vertical jump, repetitive push-ups, sit-ups, grip strength, bench press) were significantly different. One of the conclusions stated very good aerobic capacity based on $\mathrm{VO}_{2}$ max values. Unfortunately, the full text of the study is not available and the abstract does not describe further details.

Gochioco (2010) reports similar results in MMA wrestlers, i.e. $53.44+-5.77 \mathrm{ml} . \mathrm{kg}^{-1}$. $\min ^{-1}$. This group was also tested for maximum performance in squats and bench press, recalculated per body mass with a result of 1.45 and 1.25 , respectively. The author also added that the stress test results were closest to judokas, whereas Greco-Roman wrestlers achieved lower values. Amateur level wrestlers who are expected to show lower values than professionals were tested.

$\mathrm{VO}_{2}$ max level was also tested by Alm (2013), and the measured capacity was around $60 \mathrm{ml} \cdot \mathrm{kg}^{-1} \cdot \mathrm{min}^{-1}$. The authors also compared running on treadmill and arm cycling, which did not show different outputs. Upper body performance parameters appeared to be more significant for overall performance than those of the lower body were. Therefore, the authors proposed to include the mentioned arm cycle in testing. Another conclusion was high tolerance 
to elevated lactate levels in elite wrestlers. They have to cope with this condition during the combat having only one minute between rounds for some recovery. If lactate levels are too high or persist for too long, it has a negative impact on both physical and mental aspect of the performance.

Addressing the physiological profile, Schick (2010) confirms above-average $\mathrm{VO}_{2}$ max values, i.e. $55.5 \pm 7.3 \mathrm{ml} . \mathrm{kg}^{-1}$. $\mathrm{min}^{-1}$, in wrestlers with a minimum of two years MMA fighting experience regardless of their performance level. The study compares the results, among others, to other martial arts, however, in our opinion it is impossible to compare amateur wrestlers to elite international level athletes. Compared to Gochioco (2010), the volunteers achieved similar results in strength tests. For the upper body bench press was selected and the average measured was $1.2 \mathrm{~kg}$ per $\mathrm{kg}$ of body mass.

A comparison of official and sparring matches was carried out in a group of professional fighters (Coswig 2016). Post-match lactate levels were comparable with mean values of 16.9

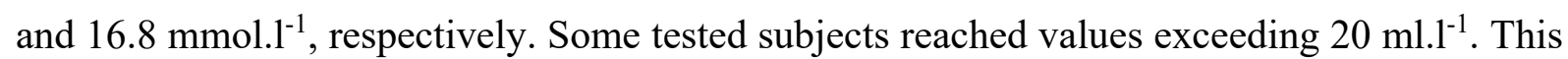
study reported no differences between winners and losers (as opposed to Amtman 2008). Athletes could use regular protective equipment during sparring, however, the motivation and coaching provided was similar to official matches. Biomarker levels (creatine kinase (CK), aspartate aminotransferase, alanine aminotransferase), showed no significant muscle damage during the match. CK values were not as high as in other studies (Weichmann 2016; Ghoul 2017). Samples were collected immediately after exercise, i.e. increase of biomarkers within 24 hours could be expected.

Weichmann (2016), who focused on muscle damage, also performed analysis of blood samples collected after official matches. Monitored markers were CK and myoglobin; high values thereof corresponded to high physical load. Peak CK values averaged $829 \mathrm{U} / \mathrm{L}^{-1}$. Nevertheless, the results were comparable to those reported for other sports, such as rugby. Also Lindsay (2017) arrived to similar conclusions, although different markers (neopterin, myoglobin) were monitored. The authors also suggest that increased levels of selected parameters could reflect un/successfully executed kicks and punches. However, they do not provide any relevant confirmation of this hypothesis.

High physiological load associated with CK elevation after exercise is described by Ghoul (2017). Specifically, average CK values 24 hours after a simulated match moved around $600 \mathrm{U} / \mathrm{L}^{-1}$. This study simultaneously monitored fluctuations of testosterone and cortisol, which were comparable to those described in more intense activities. This research included, among others, also the effect of cold water on various blood values and performance tests. For this 
intervention, the conclusions were not in ambiguous, especially in the dynamic-strength tests. To speed up the overall regeneration after a very demanding MMA training as much as possible, cold water seems to be a possible means (see also Tabben 2018).

Research focused on other martial arts, such as boxing, kick-boxing, judo, greek-coronet wrestling, taekwondo, and so on, provides a certain comparison. In general, the tested athletes reached higher $\mathrm{VO}_{2}$ values, the highest ones, about $60 \mathrm{ml} \cdot \mathrm{kg}^{-1} \cdot \mathrm{min}^{-1}$, being reported in boxers (Lenetsky 2012). The results confirm that very good aerobic fitness is important for most combat sports. In upper body strength testing, bench press is included serving as a good indicator of pressure strength and absolute strength. High performance is typical for judokas and Greco-Roman wrestlers. This component appears to be a good testing criterion for MMA. The statistics also show that taekwondo and thai boxing share the fewest common physiological traits with MMA. These conclusions should be taken into account when implementing specific training methods that should be optimized specifically for MMA.

Some studies (Ghoul 2017; Alm 2013; James 2016) have investigated performance in various strength and dynamic-power techniques. However, these data are too scarce for any conclusions. So far, the most frequently used test is the bench press, which seems to be a good indicator of performance (as opposed to the back squat). However, the researchers are moving towards analyses of exercises where athletes use their own body or towards conversion of performance relative to body mass, which could be more informative than the absolute performance. Due to the great variability of MMA, it is difficult to find adequate strength tests overlapping with the overall performance of the wrestler. However, performance of different weight categories should be distinguished because, as results from other sports disciplines show (Storey 2012), they cannot be considered as constant.

Figure 1 lists studies dealing with physiological aspects. So far, their number is relatively small. We are sorry to say that the evidence of most research is weak. Investigated samples usually include only a small number of subjects showing, moreover, different performance levels. Weight categories with their logical differences are not sufficiently respected either.

\section{Injuries}

MMA ranks among those martial arts that logically attract attention to the aspect of injuries. Here we mean especially injury caused by the opponent, no matter if it is during training or a match. Again, examples may be taken from other martial arts such as boxing, kick boxing, Brazilian jiu-jitsu, judo, and others (Pocecco 2013). However, even here, MMA has its 
specifics and a complex combination of various combat styles in synergy with its own techniques extends the repertoire of possible injuries.

A study by Jensen (2017) compared MMA and other combat sports from the aspect of injuries. Its statistics yielded that most injuries occur during training and only a third to a fifth thereof during the match itself. Injuries vary also depending on the nature of the sport. Typical injuries in judo or Greco-Roman wrestling are joint injuries (elbows, shoulders), in boxing or kick-boxing they are primarily head and face injuries. This indicates that in injury prophylaxis attention should be paid to preparatory periods.

In this context (Miarka 2018) states that the main reason for a doctor to stop a match (doc-stoppage) are head injuries in more than $90 \%$ of cases, namely lacerations (80\%). Interestingly, this most often happens during the second round, due to so-called striking. In an analysis of 635 matches from 2002 - 2007, Ngai (2008) reports injury rate of $23 \%$, of which $3 \%$ were severe concussions. According to the author, these numbers are comparable to those in other stance combat sports (see also Bledsoe 2006), which is, however, in disagreement with other authors (Lystad 2014; Pocecco 2013).

A MMA-only meta-analysis showed that the most commonly injured region was the head, accounting for $66-78 \%$ of injuries, followed by hand and wrist accounting for $6-12 \%$ of cases (Lystad 2014). The most frequent injury types were laceration (36-59\%), fractures varied from 4 to $43 \%$. As regards injury rate, MMA ranks among martial arts with the highest number of injuries per 1000 matches (athlete-exposure). These findings agree with Lystad (2015), however, the highest absolute number of head injuries was reported for boxers.

The risk factor of injury constantly rises with increasing weight category and is also higher in title matches. It is not surprising that the risk of injury is three times greater in losers than in winners. Curran-Sills (2018) arrived to comparable conclusions with Canadian professional wrestlers. Over five years, there were 162 injuries (in 686 athletes) during 35 events. Again, the most common was head injury. Ji (2016) stated different results in Korean wrestlers, reporting arm and neck as the most commonly injured body parts, the head coming next. However, at the same time, lacerations and brain concussions were reported as the most common type of injury.

The analysis by McClain (2014) provides a more positive statistic showing "only" an $8.5 \%$ risk of injury, as opposed to that of $23-28 \%$ reported elsewhere (Bledsoe 2006; Ngai 2008 etc.). However, the diverse performance levels, including amateur matches, should be taken into account. It is possible that it is just in lower performance level matches where the risk of injury is not so high. However, this is still an unconfirmed hypothesis. 
Hutchison (2014) performed an analysis of UFC matches dating from 2006 - 2012. Knockout or technical knockout was recorded in $31.9 \%$ of cases. Although this is not directly linked to an obvious injury, knockout presumes strong blows to the head often associated with short-term unconsciousness or other trauma. Given these findings, the authors propose to forbid MMA in wrestling form to children and youth. The concept of events and the sport itself seem problematic in this respect. Unlike other sports, where after a strong blow the athlete is sent to the ground (knock down) and the match is in fact interrupted so that the referee may check the health status of the fighter. In MMA, the whole action must be judged by the referee "on the move" during the match and the moment when the referee intervenes means the end.

Martial arts are mostly a male affair, however, at a professional level, women form a regular part of MMA events. Research studies involving female wrestlers provide little information so far to enable any conclusions (Thomas 2018).

Thus, MMA is classified among sports with frequent blows to the head. This probably represents the highest risk as regards to serious permanent consequences. However, little information is available so far on the long-term effect on the neurological apparatus of MMA fighters. Box, where the risk is similar, can be regarded as a relevant comparison. A review by Heilbronner (2009) lists many studies documenting the impact of boxing on various neuropsychological markers. It should be noted that there is also research reporting no difference in cognitive abilities between boxers and a control group. The frequency of concussions appears to be the main problem. This has also been confirmed by Mishra (2018), where cognitive impairment has been reported in boxers and MMA fighters using magnetic resonance imaging.

It is certain that MMA ranks among risky sports as regards injuries (both during matches and during training). However, as regards health condition of the athlete, long-term consequences due to serious injuries and repeated head concussions are much more important. It is in this very respect that further research is needed (see also Thomas 2018).

\section{Conclusion}

Studies show that in MMA wrestlers high lactate levels are observed during standard load that corresponds also to subjective RPE. High intensity is characteristic for not only training but also official matches. However, its specific nature is not invariant and depends strongly on the course of the match. Nevertheless, the wrestler must be physically and mentally 
ready to work with that. Very good physical condition necessary for MMA is reflected in VO2 max testing, where above-average results are achieved. High cardiovascular muscle load manifests as a rise in blood markers such as CK. This implies that it is necessary to regularly include units with a high RPE in the training and, at the same time, to emphasize observing consistent regeneration time associated with optimum workload of the athlete.

Although results are not unambiguous, MMA does not stand out from other combat sports as regards injuries. From a probabilistic point of view, the risk of injury is higher, especially as regards head injury. Attention should be paid not only to matches, but also to training sessions.

They also bring a higher risk of injury because of specific high-intensity preparation (e.g. simulated match - sparring). Because of frequent blows to the head, wrestlers risk permanent consequences. Therefore, this aspect must be taken into account in the overall concept of training and sports career. It is important to emphasize that most of the presented data is more than 10 years old. MMA is a fast-changing sport, and there is a positive trend in considering health condition of wrestlers (referee interventions, forced breaks after knock out, mandatory examinations, etc.).

Further research is necessary to confirm some of the conclusions. The main limitation is the size of the monitored subject samples, which is often small and very heterogeneous (different performance level, weight category, etc.) or not so up-to-date data. 


\begin{tabular}{|c|c|c|c|c|c|c|c|c|c|}
\hline & $\mathbf{N}$ & $\operatorname{sex}$ & age & $\begin{array}{l}\text { training } \\
\text { experience }\end{array}$ & $\begin{array}{c}\mathrm{V}-\mathrm{O}_{2} \mathrm{max} \\
(\mathrm{mL} / \mathrm{kg} / \mathrm{min})\end{array}$ & $\begin{array}{l}\text { lactate } \\
\left(\text { mmol. } L^{-1}\right)\end{array}$ & CK (U/L) & $\begin{array}{c}\text { total } \\
\text { neopterin } \\
\text { (mmol/sG) }\end{array}$ & main outcome \\
\hline Amtmann (2008) & 6 & male & $21-41$ & amateur & & $\begin{array}{c}8,1-19,7 / \\
10,2-20,7 \\
\text { (postbout) }\end{array}$ & & & $\begin{array}{l}\text { high level of lactate } \\
\text { during training. } \\
\text { interval training as } \\
\text { an important part of } \\
\text { training }\end{array}$ \\
\hline Braswell (2010) & 12 & male & $18-36$ & $\begin{array}{c}\text { professional, } \\
\text { amateur }\end{array}$ & & & & & $\begin{array}{c}\text { comparable results } \\
\text { of VO2 max with } \\
\text { karate }\end{array}$ \\
\hline Alm (2013) & 5 & male & $29,5 \pm 5,5$ & elite & $60,5 \pm 5,1$ & $\begin{array}{c}14,02 \pm \\
5,16\end{array}$ & & & $\begin{array}{l}\text { high aerobic } \\
\text { capacity, no } \\
\text { significant } \\
\text { improvement in } \\
\text { physical } \\
\text { parameters during } \\
\text { the year }\end{array}$ \\
\hline Coswig (2016) & 25 & male & $26,5 \pm 5$ & professional & & $\begin{array}{l}13,8-23,5 / \\
12,3-19,2\end{array}$ & $\begin{array}{c}159,7-394 \\
5 / 208,5- \\
403,5\end{array}$ & & $\begin{array}{l}\text { official and } \\
\text { simulated matches } \\
\text { have a comparable } \\
\text { load, glucose level } \\
\text { rises before the } \\
\text { official match }\end{array}$ \\
\hline Ghoul (2017) & 12 & male & $26 \pm 5$ & professional & & $13,6 \pm 1,4$ & $598-451$ & & $\begin{array}{c}\text { correlation between } \\
\text { biomarkers, motor } \\
\text { tests and RPE }\end{array}$ \\
\hline Lindsay (2017) & 15 & male & $28,3 \pm 5,7$ & $\begin{array}{c}\text { semi- } \\
\text { professional }\end{array}$ & & & & 14000 & $\begin{array}{l}\text { high structural and } \\
\text { inflammatory } \\
\text { stress, cold water } \\
\text { immersion as useful } \\
\text { recovery strategy }\end{array}$ \\
\hline Schick (2010) & 11 & male & $25,5 \pm 5,7$ & $\begin{array}{c}\text { amateur, } \\
\text { professional }\end{array}$ & $50,6-60,4$ & & & & $\begin{array}{l}\text { comparable } \\
\text { parameters with } \\
\text { judo, wrestling. } \\
\text { average grip } \\
\text { strength }\end{array}$ \\
\hline Tabben (2018) & 12 & male & $26 \pm 5$ & professional & & & & & $\begin{array}{l}\text { same study - Ghoul } \\
\text { (2017), mixed effect } \\
\text { of applying cold } \\
\text { water to } \\
\text { physiological } \\
\text { markers and } \\
\text { performance }\end{array}$ \\
\hline Weichman (2016) & 10 & male & $28,3 \pm 5,7$ & elite & & & $829 \pm 753$ & & $\begin{array}{c}\text { pronounce increase } \\
\text { of CK and } \\
\text { myoglobin after } \\
\text { official match }\end{array}$ \\
\hline Gochioco (2010) & 8 & male & $26,8 \pm 6,06$ & amateur & $53,44 \pm 5,77$ & & & & $\begin{array}{l}\text { lower values than } \\
\text { judoist, comparable } \\
\text { to wrestlers }\end{array}$ \\
\hline
\end{tabular}

Figure 1

Summary of studies examining physiological aspects in MMA

\section{References}

1. ALM, P., 2013. Physiological Characters in Mixed Martial Arts. American Journal of Sports Science. 1, 12-17. 
2. AMTMANN, J. A., K. A. AMTMANN \& W. K. SPATH, 2008. Lactate and Rate of Perceived Exertion Responses of Athletes Training for and Competing in a Mixed Martial Arts Event. Journal of Strength and Conditioning Research. 22, 645-647.

3. BLEDSOE, G. H., E. B. HSU, J. G. GRABOWSKI, J. D. BRILL \& G. LI, 2006. Incidence of injury in professional mixed martial arts competitions. 7, 136-142.

4. BRASWELL, M. T. et al., 2010. Physiological Differences In Mixed Martial Artist And Traditional Martial Artists: A Pilot Study: Journal of Strength and Conditioning Research. 24(1).

5. CURRAN-SILLS, G. \& T. ABEDIN, 2018. Risk factors associated with injury and concussion in sanctioned amateur and professional mixed martial arts bouts in Calgary, Alberta. BMJ Open Sport \& Exercise Medicine 4.

6. GALETTA, K. M. et al., 2011. The King-Devick test as a determinant of head trauma and concussion in boxers and MMA fighters. Neurology. 76, 1456-1462.

7. GHOUL, N. et al., 2017. Mixed martial arts induces significant fatigue and muscle damage up to 24 hours post-combat. Journal of Strength and Conditioning Research 1.

8. GOCHIOCO, M. et al., 2010. Physiological profile of amateur mixed martial artists. Medicine \& Science in Sports \& Exercise. 42, 837-838.

9. HEILRONNER, R. L. et al., 2009. Neuropsychological Consequences of Boxing and Recommendations to Improve Safety: A National Academy of Neuropsychology Education Paper. Archives of Clinical Neuropsychology. 24, 11-19.

10. HUTCHINSON, M. G., D. W. LAWRENCE, M. D. CUSIMANO \& T. A. SCHWEIZER, 2014. Head Trauma in Mixed Martial Arts. The American Journal of Sports Medicine. 42, $1352-1358$.

11. JAMES, L. P., G. G. HAFF, V. G. KELLY \& E. M. BECKMAN, 2016. Towards a Determination of the Physiological Characteristics Distinguishing Successful Mixed Martial Arts Athletes: A Systematic Review of Combat Sport Literature. Sports Medicine. 46, 1525-1551.

12. Jensen, A. R., R. C. MACIEL, F. A. PetriglianO, J. P. RODRigueZ \& A. G. BROOKS, 2016. Injuries Sustained by the Mixed Martial Arts Athlete. Sports Health: A Multidisciplinary Approach. 9, 64-69.

13. JI, M., 2016. Analysis of injury types for mixed martial arts athletes. The Journal of Physical Therapy Science. 28, 1544-1546. 
14. LANDERS, M. R., R. DONATELLI, J. NASH \& R. BASCHARON, 2017. Evidence of dynamic visual acuity impairment in asymptomatic mixed martial arts fighters. Concussion 2,3 .

15. LENETSKY, S. \& N. HARRIS, 2012. The Mixed Martial Arts Athlete: A Physiological Profile. Strength and Conditioning Journal. 34, 32-47.

16. LINDSAY, A. et al., 2017. The physiological response to cold-water immersion following a mixed martial arts training session. Applied Physiology, Nutrition, and Metabolism. 42, $529-536$.

17. LYSTAD, R. P., 2015. Epidemiology of injuries in full-contact combat sports. Australasian Epidemiologist. 22(6).

18. LYSTAD, R. P., K. GREGORY \& J. WILSON, 2014. The Epidemiology of Injuries in Mixed Martial Arts: A Systematic Review and Meta-analysis. Orthopaedic Journal of Sports Medicine. 2, 232596711351849.

19. McCLAIN, R. et al., 2014. Injury Profile of Mixed Martial Arts Competitors. Clinical Journal of Sport Medicine. 24, 497-501.

20. MISHRA, V. R. et al., 2017. Multimodal MR. Imaging Signatures of Cognitive Impairment in Active Professional Fighters. Radiology. 285, 555-567.

21. NGAI, K. M., F. LEVY \& E. B. HSU, 2008. Injury trends in sanctioned mixed martial arts competition: a 5-year review from 2002 to 2007. British Journal of Sports Medicine. 42, 686-689.

22. POCECCO, E. et al., 2013. Injuries in judo: a systematic literature review including suggestions for prevention. British Journal of Sports Medicine. 47, 1139-1143.

23. SAVAGE-WEST, R., 2015. From rags to riches: The rise and rise of the UFC (or will oversaturation lead to its downfall). Laws of the game. 1, 1-11.

24. SCHICK, M. G., L. E. BROWN \& E. E. SCHICK, 2012. Strength and Conditioning Considerations for Female Mixed Martial Artists. Strength and Conditioning Journal. 34, $66-75$.

25. SCHICK, M. G. et al., 2010. Physiological Profile of Mixed Martial Artists. Medicina Sportiva. 14, 182-187.

26. COSWIG S. et al., 2016. Biochemical Differences Between Official and Simulated Mixed Martial Arts (MMA) Matches. Asian Journal of Sports Medicine. 7(2).

27. STOREY, A. \& H. K. SMITH, 2012. Unique Aspects of Competitive Weightlifting. Sports Med. 42, 796-90. 
28. TABBEN, M. et al., 2018. Cold Water Immersion Enhanced Athletes' Wellness and 10-m Short Sprint Performance 24-h After a Simulated Mixed Martial Arts Combat. Frontiers in Physiology. 9, 1542.

29. THOMAS, R. E. \& B. C. THOMAS, 2018. Systematic review of injuries in mixed martial arts. The Physician and Sportsmedicine. 46, 155-167.

30. WIECHMANN, G. J., E. SAYGILI, C. ZILKENS, R. KRAUSPE \& M. BEHRINGER, 2016. Evaluation of muscle damage marker after mixed martial arts matches. Orthopedic Reviews. 8, 6209. 